\title{
Drug use and/or exposure in pregnancy: Presence of risk versus quantity of risk
}

To the Editor,

The case report by Karataş et al. (1), published in the fourth issue of the Journal of the Turkish German Gynecological Association in December 2014 was interesting. This report identified an infant with multiple cardiovascular malformations, whose mother was exposed to carbamazepine (CBZ) during pregnancy. This case report is well presented, and authors have provided a well-thought discussion. Nevertheless, I would like to mention some points relevant to the interpretation of human data in the field of teratology which may widen the readers' perspective regarding the management of drug exposure and/ or use in pregnancy.

Case reports are very useful in terms of noticing rare and repeating patterns; however, they cannot provide any estimates regarding the absolute risk of malformations since they lack a denominator. The absolute risk is only available through the interpretation of epidemiological data from observational cohorts or case-control studies (2).

For a particular drug, being a teratogen or posing an unacceptable risk for use in pregnancy are two different concepts. A drug with established teratogenic effect may not always heighten the risk of teratogenicity to inacceptable levels, and CBZ is a good example for that. Although the risk for spina bifida may increase 2-10-fold after CBZ exposure, considering the prevalence of this malformation (1:1000), the absolute risk would still be small $(0.2 \%-1 \%$ vs $0.1 \%)$ (3). A review of available epidemiological studies by the American Academy of Neurology and American Epilepsy Society subcommittees have shown that CBZ probably does not lead to a substantial increase in the risk of major congenital malformations and it is relatively safe in terms of major congenital malformations and neurodevelopmental outcomes when compared to other classical antiepileptic such as valproic acid (VPA) (4). A recent meta-analysis also suggests that CBZ is not associated with adverse neurodevelopmental outcomes in infants (5).

Therefore, in terms of absolute risk, CBZ has a relatively safe profile compared with other conventional antiepileptic drugs (AEDs), such as VPA, and still remains to be an option for the management of pregnant patients with epilepsy (5). When discussing the possible risks regarding drug use or exposure in pregnancy, the very first information that should be received by pregnant women is the rate for background risk of malformations (3\%), which is present in every pregnancy regardless of an exposure (2). Afterwards, the available data regarding the drug, with considering possible confounders, should be discussed. Finally, an individual risk assessment and risk communication should be available to all pregnant women who may need drug treatment for their chronic diseases, not only in terms of the presence of risk but also in terms of the quantity of risk.

Yusuf Cem Kaplan

TERAFAR-İzmir Kâtip Çelebi University Teratology Information, Training and Research Center, İzmir, Turkey

\section{References}

1. Karataş Z, Karataş A, Özlü T, Goksugur SB, Varan B. Bicuspid aortic valve and severe aortic stenosis in a newborn exposed to carbamazapine during pregnancy. J Turk Ger Gynecol Assoc 2014; 15: 259-61. [CrossRef]

2. Koren G, Pastuszak A, Ito S. Drugs in pregnancy. N Engl J Med 1998; 338: 1128-37. [CrossRef]

3. Matlow J, Koren G. Is carbamazepine safe to take during pregnancy? Can Fam Physician 2012; 58:163-4.

4. Harden CL, Meador KJ, Pennell PB, Hauser WA, Gronseth GS, French JA et al. Practice parameter update: management issues for women with epilepsy-focus on pregnancy (an evidence based review): teratogenesis and perinatal outcomes. Epilepsia 2009; 50: 1237-46. [CrossRef]

5. Bromley R, Weston J, Adab N, Greenhalgh J, Sanniti A, McKay AJ, et al. Treatment for epilepsy in pregnancy: neurodevelopmental outcomes in the child. Cochrane Database Syst Rev 2014; 10: CD010236. [CrossRef]

\section{Author's Response}

We thank the authors for their contribution to the paper. As we mentioned in the manuscript, carbamazepine is relatively safe in terms of major congenital malformations and neurodevelopmental outcomes when compared with other classical antiepileptic drugs (AEDs), such as valproic acid. Nevertheless, we again want to emphasize that the infants exposed to AEDs during pregnancy should be followed because the risk of congenital malformations may rarely occur. Furthermore, to prevent these risks, AEDs should be reduced to the lowest possible dose from the beginning of the preconception period and supplementation of folic acid should be considered.

\section{Ahmet Karataş \\ Department of Obstetrics and Gynecology, Abant İzzet Baysal University Faculty of Medicine, Bolu, Turkey}

